\title{
Polysaccharide-protein conjugate vaccination induces antibody production but not sustained B-cell memory in the human nasopharyngeal
}

\section{mucosa}

\author{
ET Clarke ${ }^{1}$, NA Williams ${ }^{1}$, PM Dull ${ }^{2}$, J Findlow ${ }^{3}$, R Borrow ${ }^{3}$, A Finn ${ }^{1}$ and RS Heyderman ${ }^{1,4}$
}

Colonization of the nasopharyngeal mucosa by meningococcus and other polysaccharide (PS)-encapsulated bacteria precedes invasion. PS-conjugate vaccines induce PS-specific B-cell memory $\left(\mathrm{B}_{\mathrm{MEM}}\right)$ and also prevent colonization, thus blocking person-to-person transmission, generating herd protection. However, in isolation the $\mathrm{B}_{\mathrm{MEM}}$ are unable to sustain immunity. Furthermore, the duration of herd protection the vaccines induce appears limited. We demonstrate that, despite the persistence of PS-specific $B_{M E M}$, the population is not maintained within the nasopharynx. Although booster immunization results in the transient appearance of PS-specific $B_{M E M}$ within the mucosa, this reflects the re-circulation of systemic $B_{M E M}$ through the site rather than the generation of resident mucosal $B_{M E M}$. The induction of sustained PS-specific $B_{M E M}$ in the nasopharynx would allow the population to be activated by colonization, thus inhibiting subsequent invasion. It would also be expected to boost local mucosal immunity, thus extending herd protection. Strategies to generate PS-specific $B_{M E M}$ in the mucosa warrant further investigation.

\section{INTRODUCTION}

Polysaccharide (PS) - protein (PT) conjugate vaccines are central to the immunization strategies available to protect against PS encapsulated bacteria, including Neisseria meningitidis, Streptococcus pneumoniae, and Haemophilus influenzae type b. ${ }^{1}$ The bacteria commonly colonize the human nasopharynx while causing invasive disease comparatively rarely. Conjugate vaccines aim to overcome important limitations of the isolated capsular PS, which reflect their nature as T-cell-independent type 2 antigens, through the recruitment of T-cell help via a conjugated carrier PT. ${ }^{1}$ They induce PS-specific B-cell memory $\left(\mathrm{B}_{\mathrm{MEM}}\right)$, as indicated by the generation of anamnestic, affinity matured antibody responses on subsequent low-dose PS challenge. ${ }^{2,3}$ They also prevent bacterial colonization of the nasopharynx, thus blocking person-to-person spread and generating the herd protection, which is considered to be an important aspect to the effectiveness of the vaccines in the population as a whole. ${ }^{4,5}$
Correlates of the immunity generated by conjugate vaccines have been defined based on the presence of PSspecific serum antibody concentrations above defined thresholds, ${ }^{6}$ but even following the waning of serum antibodies, it was expected that protection would be maintained in vaccinated individuals through the activation of PS-specific $B_{\mathrm{MEM}}{ }^{1}$ However, following the widespread introduction of conjugate vaccines into national immunization schedules, it has become increasingly clear that this premise is unreliable and that, in the absence of sustained serum antibody concentrations, protection is at best inconsistent. ${ }^{7,8}$ This lack of protection does not appear to reflect a loss of PS-specific $\mathrm{B}_{\mathrm{MEM}}$, as anamnestic antibody responses, triggered by subsequent invasive disease, have been described in cases of vaccine failure. ${ }^{7,9}$ Instead, it therefore appears to represent a mismatch between the time taken to activate $\mathrm{B}_{\mathrm{MEM}}$ on initial bacterial encounter and the subsequent progression of clinical disease in the context of waning herd protection. ${ }^{1,7}$

${ }^{1}$ School of Cellular and Molecular Medicine, University of Bristol, Bristol, UK. ${ }^{2}$ Clinical Development, Novartis Vaccines and Diagnostics, Cambridge, Massachusetts, USA. ${ }^{3}$ Vaccine Evaluation Unit, Health Protection Agency, Public Health Laboratory, Manchester Royal Infirmary, Manchester, UK. ${ }^{4}$ Malawi-Liverpool-Wellcome Trust Clinical Research Programme, University of Malawi College of Medicine, Blantyre, Malawi. Correspondence: ET Clarke (Ed.Clarke@bristol.ac.uk) 
We have explored the hypothesis that the failure of the $\mathrm{B}_{\mathrm{MEM}}$ to maintain protection reflects a failure of parenteral vaccination to generate a sustained population in the nasopharynx. Using a Men ACWY-CRM ${ }_{197}$ conjugate vaccine with established systemic immunogenicity, ${ }^{2,3,10-13}$ we show that parenteral vaccination induces an increase in PS-specific antibodies within the nasopharynx, which may prevent bacterial colonization. However, although newly generated PS-specific $\mathrm{B}_{\mathrm{MEM}}$ also appears transiently within the local mucosal immune tissue, they are not maintained at this site. Furthermore, in contrast to the concurrently generated PT-specific $\mathrm{B}_{\mathrm{MEM}}$, the PS-specific $\mathrm{B}_{\mathrm{MEM}}$ do not continue to re-circulate through the nasopharyngeal mucosa and, hence, do not appear to undertake ongoing immune surveillance of the site.

The findings highlight residual differences apparent in the immune responses generated against PS and PT antigens, despite their presentation in conjugated form. They suggest that novel strategies, targeting $\mathrm{B}_{\mathrm{MEM}}$ to the mucosa, may overcome what has appeared to be a critical limitation of the conjugate vaccines, through both reducing the frequency of progression to invasive disease following colonization and also through sustaining herd protection in the population.

\section{RESULTS}

To allow the mucosal immune responses generated in the human nasopharynx by a Men ACWY-CRM ${ }_{197}$ conjugate vaccine to be examined in detail, otherwise, healthy adult volunteers $(n=32)$ were recruited before tonsillectomy. None of the subjects had received a Men A-, Men $\mathrm{W}_{135^{-}}$, or Men Y-containing vaccine previously. A group of subjects who had received a single Men $C$ conjugate vaccine between 5 and 6 years before the current study $\left(\mathrm{C}_{\text {PRIMED }}\right)$, and a group of individuals who were naive to the vaccine $\left(\mathrm{C}_{\mathrm{NAIVE}}\right)$ were recruited, allowing the effects of prior Men C conjugate vaccination on the mucosal responses to be determined. All the subjects had received full five dose diphtheria toxoid (DT) and tetanus toxoid (TT) vaccination courses, although none in the interval since they had received the Men $\mathrm{C}$ vaccine.

\section{Conjugate vaccines generate sustained salivary as well as serum antibodies that are boosted by parenteral challenge}

In order to compare the mucosal immunity generated by the Men ACWY vaccine with its established systemic immunogenicity,,$^{2,3,10-13}$ the serological responses to the vaccine were initially examined within the study cohort. Before vaccination, the Men $\mathrm{C}$ concentrations were significantly higher in the $\mathrm{C}_{\text {PRIMED }}$ subjects than in the $\mathrm{C}_{\mathrm{NAIVE}}$ individuals (mean \pm s.e.m.; $24.6 \pm 14.1$ vs. $1.6 \pm 0.9 \mu \mathrm{g} \mathrm{ml}^{-1} ; P<0.05$; Figure 1b) confirming the previously reported persistence of systemic antibodies for at least 5 years following Men C conjugate vaccination in early adulthood. ${ }^{14}$ As expected, the Men ACWY vaccine induced significant increases in the antibody concentrations specific for all four PS (Figure 1a-d). However, the magnitude of the increase (104.8 \pm 28.0 vs. $21.3 \pm 11.9 \mu \mathrm{g} ; P<0.05$ ) and, hence, the subsequent antibody concentrations (Figure $\mathbf{1 b}$ ) were significantly higher in the $\mathrm{C}_{\text {PRIMED }}$ subjects than in the $\mathrm{C}_{\text {NAIVE }}$ individuals, suggesting the response of a PS-specific $\mathrm{B}_{\mathrm{MEM}}$ population generated by priming in the former group.
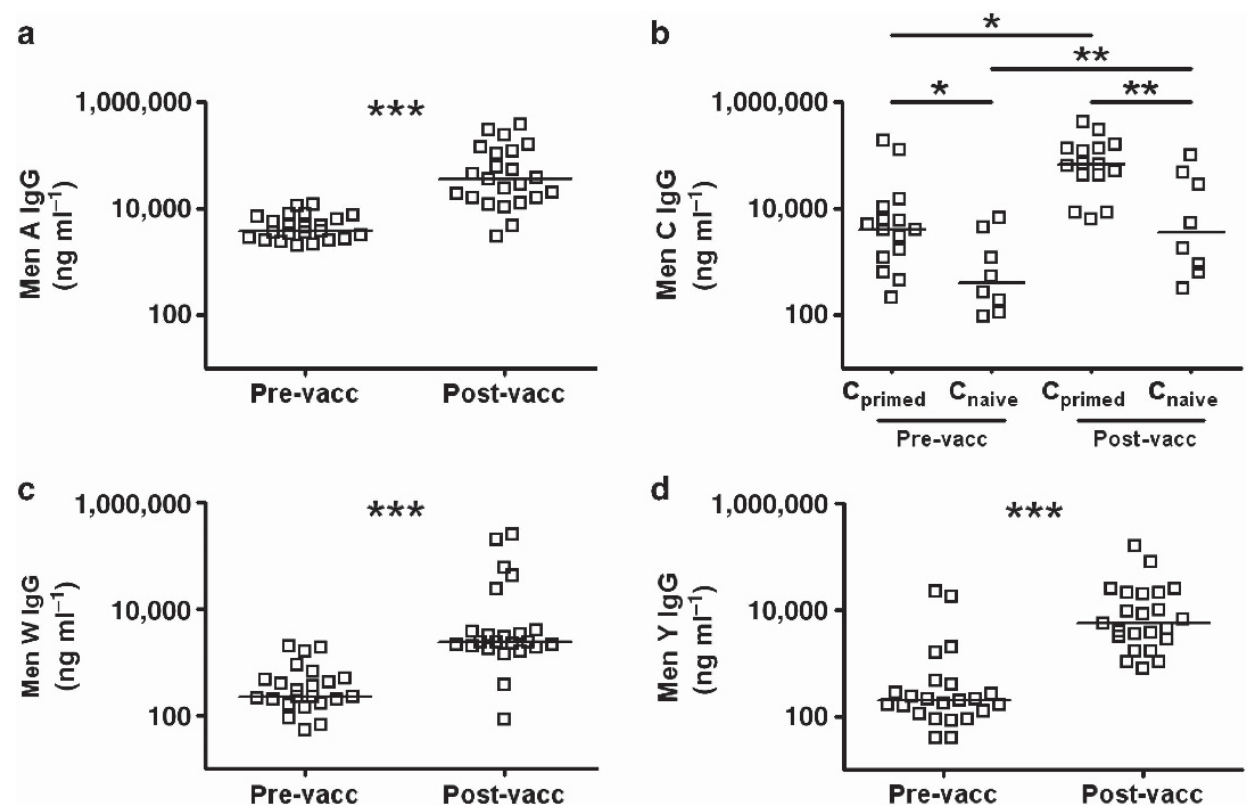

Figure 1 Antigen-specific serum IgG concentrations pre- and post administration of a Men ACWY vaccine. Graphs comparing the serum (a) Men A-, (b) Men C-, (c) Men $\mathrm{W}_{135^{-}}$, and (d) Men Y-specific IgG concentrations in study subjects $(n=23)$ before and 4 weeks following the administration of the Men ACWY vaccine. All subjects are included in the columns illustrating the Men A-, Men $\mathrm{W}_{135^{-}}$, and Men Y-specific IgG concentrations. $\mathrm{C}_{\mathrm{PRIMED}}$ $(n=15)$ and $\mathrm{C}_{\text {NAIVE }}(n=8)$ subjects are shown separately in the columns illustrating the Men C-specific IgG concentrations; multiple comparisons made using a one-way analysis of variance (Freidman's Test) with Dunn's multiple comparison tests. Paired data were compared using two-tailed Wilcoxon matched pairs tests; ${ }^{* \star *} P<0.001,{ }^{\star \star} P<0.01,{ }^{\star} P<0.05$. Post-vacc, post-vaccine; Pre-vacc, pre-vaccine. 

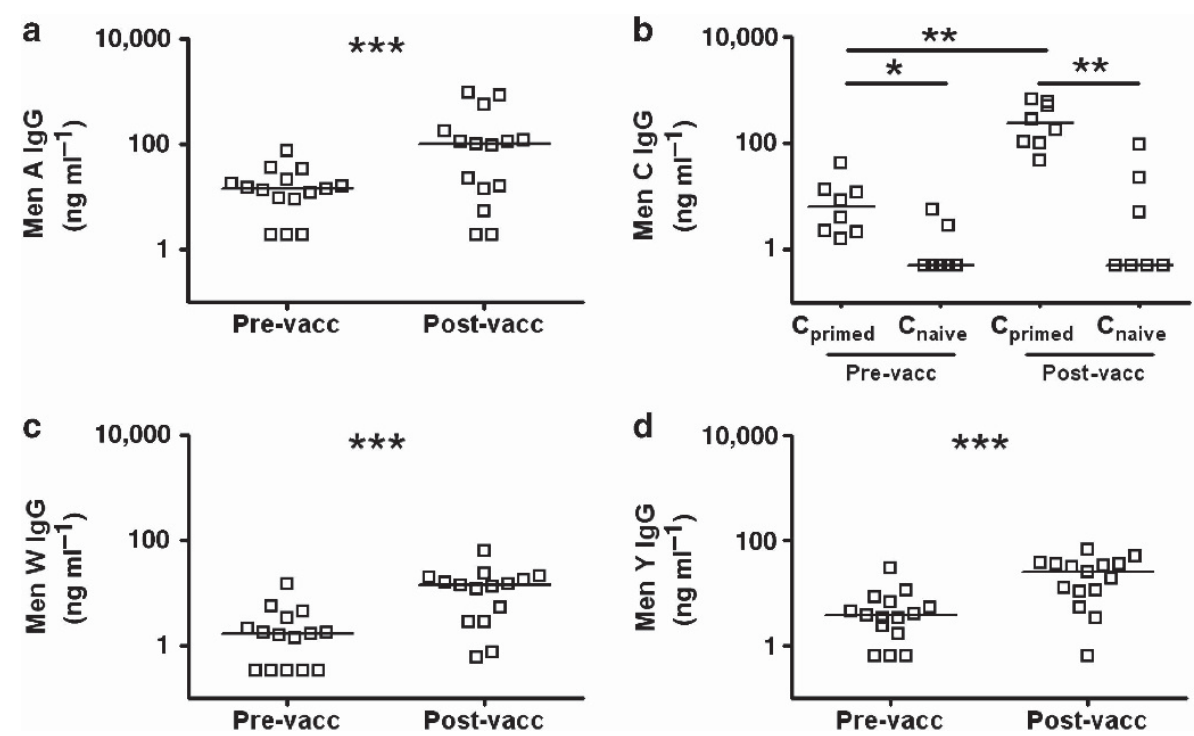

Figure 2 Antigen-specific salivary IgG concentrations pre- and post administration of a Men ACWY vaccine. (a-d) Graphs comparing the salivary (a) Men A-, (b) Men C-, (c) Men $\mathrm{W}_{135^{-}}$, and (d) Men Y-specific IgG concentrations in study subjects $(n=15)$ before and 4 weeks following the administration of a Men ACWY vaccine. All subjects are grouped in the graphs illustrating the Men A-, Men $\mathrm{W}_{135^{-}}$, and Men $\mathrm{Y}$-specific concentrations. $\mathrm{C}_{\text {PRIMED }}(n=8)$ and $\mathrm{C}_{\text {NAIVE }}(n=7)$ subjects are shown separately in the graphs illustrating the Men C-specific concentrations. Multiple comparisons made using a one-way analysis of variance (Freidman's test) with Dunn's multiple comparison tests. Paired data were compared using two-tailed Wilcoxon matched pairs tests; ${ }^{* \star *} P<0.001,{ }^{* \star} P<0.01,{ }^{\star} P<0.05$. Post-vacc, post-vaccine; Pre-vacc, pre-vaccine.

Both before vaccination (Men A: $4.8 \pm 0.6 ;$ Men $_{135}: 0.5 \pm 0.1$, $P<0.001$; Men Y: $\left.2.0 \pm 1.2 \mu \mathrm{g} \mathrm{ml}^{-1} ; P<0.001\right)$ and after vaccination (Men A: 78.1 \pm 20.5 ; Men $\mathrm{W}_{135}: 26.1 \pm 13.2, P<0.01$; Men Y: $\left.17.8 \pm 7.1 \mu \mathrm{g} \mathrm{ml}^{-1} ; P<0.05\right)$, the Men A concentrations were also significantly higher across the cohort than either the Men $\mathrm{W}_{135}$ or the Men Y concentrations.

Baseline salivary IgG antibody concentrations specific for the four meningococcal PS were then compared with those induced by the Men ACWY vaccine across the cohort. Consistent with the serological responses, vaccination induced significant increases in salivary IgG concentrations specific for the four meningococcal PS (Figure 2a-d), although there was no correlation between the individuals' serum and salivary IgG concentrations either before or following vaccination $\left(r^{2}=0.009-0.2 ; P=0.09-0.92\right)$. Nonetheless, the Men C IgG concentrations in the saliva before vaccination were again higher in the $\mathrm{C}_{\mathrm{PRIMED}}$ subjects than in the $\mathrm{C}_{\mathrm{NAIVE}}$ individuals ( $10.3 \pm 4.6$ vs. $1.6 \pm 0.8 \mathrm{ng} \mathrm{ml}^{-1}$; $P<0.05)$, and this pattern was maintained following the Men ACWY vaccine ( $306.4 \pm 85.62$ vs. $17.5 \pm 13.0 \mathrm{ng} \mathrm{ml}^{-1} ; P<0.01$; Figure $2 \mathbf{b}$ ) indicating a boosting of the salivary antibodies by the parenteral route.

\section{Booster conjugate vaccination induces the transient entry of PS-specific $B_{\text {MEM }}$ into the circulation}

The induction and subsequent systemic re-circulation of $B_{M E M}$ was next explored. Before the Men ACWY vaccine, no Men $C B_{\text {MEMs }}$ were identified in the blood stream irrespective of an individual's prior vaccination status $\left(\mathrm{C}_{\mathrm{PRIMED}}\right.$ or $\mathrm{C}_{\mathrm{NAIVE}}$; Figure 3b). Men A (Figure 3a), Men $\mathrm{W}_{135}$ (Figure 3c), and Men $Y$ (Figure 3d) $B_{\text {MEM }}$ were similarly absent at the same time point. In contrast, DT $\mathrm{B}_{\mathrm{MEMs}}$ were found in the circulation in majority of subjects (Figure 3e). Even when the $\mathrm{C}_{\mathrm{PRIMED}}$ subjects were examined in isolation, there was significantly more DT, than Men $\mathrm{C}_{\mathrm{MEM}}$ present in the circulation before boosting (Figure 3f), although none of the subjects had received a vaccine containing either antigens in the preceding 5-6 years.

Men ACWY vaccination generated in a significant increase in the number of Men $C B_{M E M}$ in the circulation of the $\mathrm{C}_{\text {PRIMED }}$ subjects (Figure $3 \mathrm{c}$ ). In contrast, there was litthe increase in the same population in the circulation of the $\mathrm{C}_{\text {NAIVE }}$ individuals. Furthermore, the vaccine induced significant levels of Men A B $B_{\text {MEM }}$ across the cohort (Figure 3b), although the majority of subjects failed to generate detectable $\mathrm{B}_{\text {MEM }}$ specific for either the Men $\mathrm{W}_{135}$ or the Men Y components (Figure 3d and $\mathbf{e}$ ).

When the magnitude of the systemic Men A and Men C $B_{\text {MEM }}$ responses were compared with the corresponding serum IgG concentrations, there were significant positive correlations (Men A: $r^{2}=0.55 ; P<0.001 ;$ Men C: $\left.r^{2}=0.23 ; P<0.05\right)$. However, as demonstrated by the number of individuals who generated robust antibody responses against the antigens in the absence of detectable $B_{M E M}$ responses, the strength of the association was limited suggesting independence of the serological and memory responses (Figure $\mathbf{4 a}$ and $\mathbf{b}$ ).

The PS-specific $B_{\text {MEM }}$ generated by conjugate vaccination transit the lymphoid tissue of the nasopharynx but are not maintained at this site

The induction and maintenance of mucosal $B_{\text {MEM }}$ within the tonsillar tissue of the nasopharynx was next explored. The group of individuals who received the Men ACWY vaccine 
a

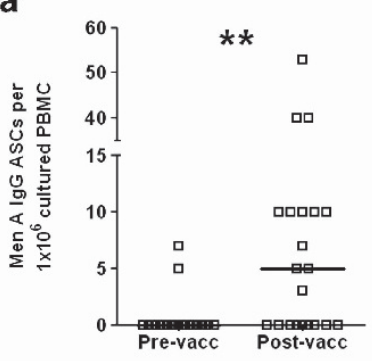

b
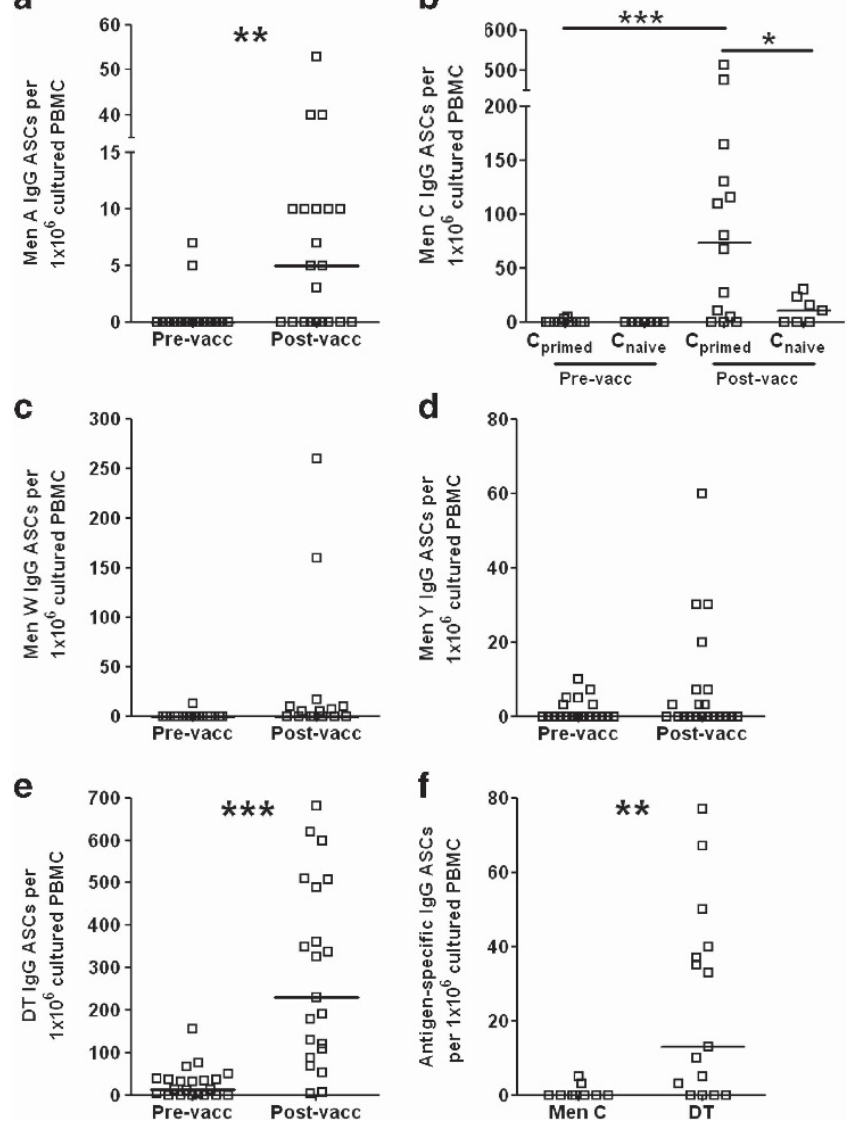

Figure 3 Antigen-specific B-cell memory $\left(B_{M E M}\right)$ response in the circulation pre- and post administration of a Men ACWY vaccine. (a-e) Graphs comparing the (a) Men A-, (b) Men C-, (c) Men $\mathrm{W}_{135^{-}}$, (d) Men Y-, and (e) diphtheria toxoid (DT)-specific $B_{\text {MEM }}$ numbers in the circulation before and 6 weeks following the administration of the Men ACWY vaccine. All subjects $(n=21)$ are grouped in the graphs illustrating the Men A-, Men $\mathrm{W}_{135^{-}}$, Men Y-, and DT-specific $\mathrm{B}_{\text {MEM }}$ responses. $\mathrm{C}_{\mathrm{PRIMED}}$ $(n=14)$ and $\mathrm{C}_{\text {NAIVE }}(n=7)$ subjects are shown separately in the graphs illustrating the Men C-specific $B_{\text {MEM }}$ responses. (f) Graph comparing the Men C- and DT-specific $B_{M E M}$ in the circulation of $C_{\text {PRIMED }}$ subjects before the administration of a Men ACWY vaccine. Paired data were compared using two-tailed Wilcoxon matched pairs tests; ${ }^{\star \star \star} P<0.001$, ${ }^{\star \star} P<0.01,{ }^{*} P<0.05$. ASC, antibody-secreting cell; PBMC, peripheral blood mononuclear cell; Post-vacc, post-vaccine; Pre-vacc, pre-vaccine.

before tonsillectomy was compared with a control group who underwent tonsillectomy but did not receive the vaccine.

As had been found in the circulation, Men $\mathrm{C}_{\mathrm{MEM}}$ were absent from the tonsils of control subjects, irrespective of their prior vaccination status with this antigen $\left(\mathrm{C}_{\mathrm{PRIMED}}\right.$ or $\mathrm{C}_{\text {NAIVE }}$; Figure 5b). Similarly, Men A (Figure 5a), Men $\mathrm{W}_{135}$ (Figure 5c), and Men $\mathrm{Y} \mathrm{B}_{\mathrm{MEM}}$ (Figure 5d) were consistently absent in the control group. In contrast, $\mathrm{DT} \mathrm{B}_{\mathrm{MEMs}}$ were present in the tonsils of the majority of control subjects (Figure 5e) and were again present significantly more frequently than the Men $\mathrm{C}_{\mathrm{MEM}}$ even in the $\mathrm{C}_{\mathrm{PRIMED}}$ group (Figure 5f). The administration of the Men ACWY vaccine before tonsillectomy resulted in the identification of significant numbers of Men $\mathrm{C} \mathrm{B}_{\mathrm{MEM}}$ in the tonsils of $\mathrm{C}_{\text {PRIMED }}$
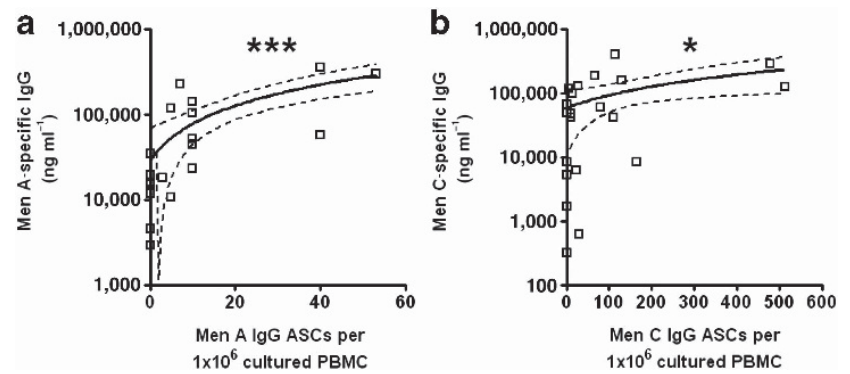

Figure 4 Correlation between the systemic polysaccharide (PS)-specific B-cell memory ( $B_{\text {MEM }}$ ) and PS-specific serum antibody concentrations. ( $\mathbf{a}$ and $\mathbf{b}$ ) Graphs showing the correlation between the (a) Men A B $B_{M E M}$ and (b) Men $C B_{M E M}$ numbers and the corresponding serum IgG concentrations $(n=20)$. Line of best fit and $95 \%$ confidence intervals calculated by linear regression are illustrated; ${ }^{* \star *} P<0.001$, ${ }^{\star} P<0.05$. ASC, antibody-secreting cell; PBMC, peripheral blood mononuclear cell.

subjects, whereas few Men $C B_{\text {MEM }}$ were identified in the $\mathrm{C}_{\text {NAIVE }}$ individuals (Figure 5b). The tonsillar Men A B numbers were also significantly higher in the vaccinated subjects across the cohort than in the unvaccinated controls (Figure 5a). There was no significant difference overall in Men $\mathrm{W}_{135}$ or Men Y $\mathrm{B}_{\text {MEM }}$ numbers when vaccinated and control groups were compared, although one or two notable individuals did respond to these antigens (Figure $5 \mathbf{c}$ and $\mathbf{d}$ ). There were also significantly higher levels of DT $\mathrm{B}_{\mathrm{MEM}}$ in the vaccinated subjects than in the control group (Figure 5e).

The kinetics of the Men $\mathrm{C} \mathrm{B}_{\mathrm{MEM}}$ responses in the tonsils demonstrated the transience of the population in the mucosa (Figure 5g), suggesting the lymphoid tissue of the nasopharynx is not a primary maintenance site for the population. The kinetics of the DT $\mathrm{B}_{\mathrm{MEM}}$ response was comparable. In this case, their number returned toward the detectable baseline levels over the same 5- to 6-week periods (Figure 5h).

There was a weak positive correlation between the magnitude of the systemic and mucosal $\mathrm{B}_{\mathrm{MEM}}$ responses for Men A $\left(r^{2}=0.23 ; P<0.05\right.$; Figure 6a), Men C $\left(r^{2}=0.43\right.$; $P<0.01$; Figure 6b), and DT $\left(r^{2}=0.23 ; P<0.05\right.$; Figure 6c), the three antigens against which significant numbers of $B_{M E M}$ had been induced. Nonetheless, the $B_{M E M}$ in the tonsils could not quantitatively have reflected only those present within the blood perfusing the tissue at the time of surgery.

\section{PT-specific, but not PS-specific, $B_{\text {MEMs }}$ are detectable in children's tonsils following routine immunizations}

The adults in this study had received a greater number of doses of DT vaccines (five) compared with Men C vaccines (one). To assess the likely importance of this difference on the level of $\mathrm{B}_{\mathrm{MEM}}$ re-circulating against the two antigens, as well as the effects of routine childhood immunizations on $B_{M E M}$ in the nasopharyngeal mucosa, a group of children $(n=15)$ between 24 and 40 months of age, who were undergoing routine tonsillectomy, were recruited. They had all received three doses of a Men $C$ conjugate vaccine and four of their scheduled vaccinations had included DT and TT, including those doses received 

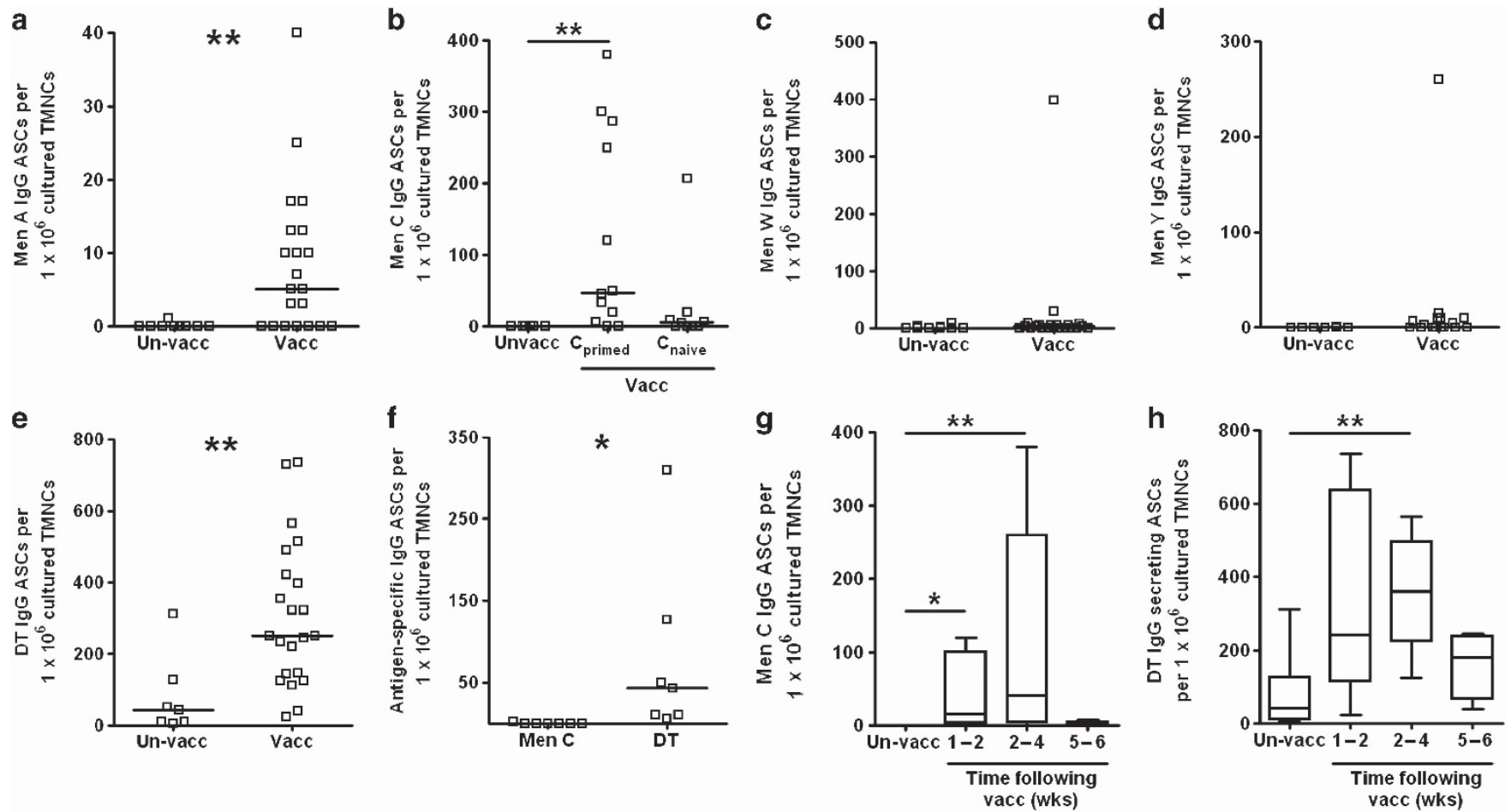

Figure 5 Tonsillar polysaccharide (PS)-specific B-cell memory $\left(B_{M E M}\right)$ following the administration of a Men ACWY vaccine. (a-e) Graphs comparing the (a) Men A-, (b) Men C-, (c) Men $\mathrm{W}_{135^{-}}$, (d) Men Y-, and (e) diphtheria toxoid (DT)-specific B-cell memory ( $\mathrm{B}_{\mathrm{MEM}}$ ) numbers in the tonsils of those subjects vaccinated with a Men ACWY vaccine (Vacc; $n=21)$ and those subjects who had not received the vaccine (Un-vacc; $n=9)$. All subjects are grouped in the graphs illustrating the Men A-, Men $\mathrm{W}_{135^{-}}$, Men Y-, and DT-specific $\mathrm{B}_{\text {MEM }}$ responses. Vaccinated $\mathrm{C}_{\text {PRIMED }}(n=12)$ and $\mathrm{C}_{\text {NAIVE }}(n=9)$ subjects are shown separately in the graphs illustrating the Men C-specific $B_{M E M}$ responses; (f) Graph comparing the Men $C$ and DT $B_{M E M}$ in the tonsils of $C_{\text {PRIMED }}$ subjects before the administration of a Men ACWY vaccine; ( $\mathbf{g}$ and $\mathbf{h}$ ) Graphs showing the (g) Men C-and (h) DT-specific $B_{\text {MEM }}$ responses in the tonsils of individuals vaccinated between 1 and 6 weeks before tonsillectomy. Paired data were analyzed using two-tailed Wilcoxon matched pairs tests; non-paired data were analyzed using a two-tailed Mann-Whitney tests; multiple comparisons were made using a one-way analysis of variance (Kruskal-Wallis) with Dunn's multiple comparisons test; ${ }^{\star \star} P<0.01,{ }^{\star} P<0.05$. TMNC, tonsillar mononuclear cell.
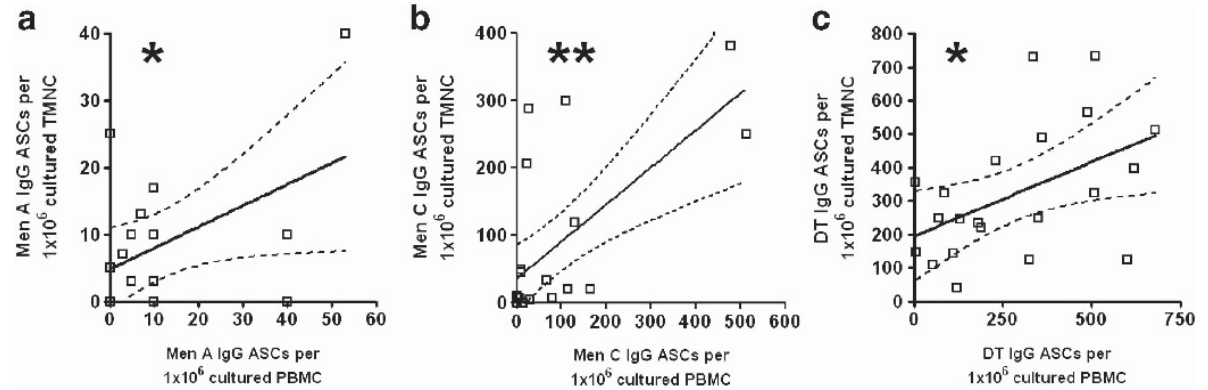

Figure 6 Correlation between the systemic and mucosal polysaccharide (PS)-specific B-cell memory ( $\mathrm{B}_{\mathrm{MEM}}$ ) responses. Graphs showing the correlation between the (a) Men A-specific, (b) Men C-specific, and (c) diphtheria toxoid (DT)-specific $B_{M E M}$ number in the circulation and the corresponding number in the tonsils following the Men ACWY vaccine $(n=21)$. Line of best fit and $95 \%$ confidence intervals calculated by linear regression are illustrated; ${ }^{\star *} P<0.01,{ }^{*} P<0.05$. ASC, antibody-secreting cell; PBMC, peripheral blood mononuclear cell; TMNC, tonsillar mononuclear cell.

in conjugate vaccine form at between 12 and 13 months. This represents the point of nearest equivalence, in terms of the number of doses of these antigens received beyond infancy, within the national immunization schedule. As the last Men C vaccine dose was in the form of a TT conjugate, administered at least 12 months before recruitment, the level of $B_{\text {MEM }}$ against these two antigens was compared in the children's tonsils. The TT $B_{\text {MEM }}$ in the tonsils of the adult cohort was also assessed to allow this additional comparison to be made and to confirm that the detectable DT $B_{M E M}$ identified in the adults was not specific to this PT. TT B $\mathrm{BEM}_{\mathrm{MEM}}$ was detected in the tonsils of both the children and adults studied although their frequency in children 
was significantly lower than their frequency in adults despite the children having been vaccinated with TT more recently (median (range); children (5.0 (0.0-83.0); adults (30.0 (15.0-393.0) per $1 \times 10^{6}$ cultured tonsillar mononuclear cell (TMNC); $\left.P<0.001\right)$. Nonetheless, TT $B_{\text {MEM }}$ was detected in the children's tonsils at significantly higher levels than Men $C \mathrm{~B}_{\text {MEM }}$ which, as in adults, was largely absent (TT (5.0 (0.0-83.0); Men C (0.0 (0.0-5.0) per $1 \times 10^{6}$ cultured TMNC; $\left.P=0.015\right)$. This suggests that the number of vaccine doses received is unlikely to be the sole factor responsible for the differences in the levels of PT and PS $B_{M E M}$ detected. It also confirms the relevance of the findings to those vaccinated according to a routine childhood schedule, in whom antibody concentrations wane most rapidly. ${ }^{15}$

\section{DISCUSSION}

This study provides evidence to support the hypothesis that the failure of the PS-specific $\mathrm{B}_{\mathrm{MEM}}$ generated by conjugate vaccines to sustain immune protection following the waning of serum antibodies reflects a failure of the vaccines to establish a long-term $\mathrm{B}_{\mathrm{MEM}}$ population within the lymphoid tissue of the nasopharynx. Despite the persistence of Men C $\mathrm{B}_{\text {MEM }}$ in the $\mathrm{C}_{\text {PRIMED }}$ individuals, the population was absent from both the blood and the tonsils before boosting. Although vaccination induced the appearance of $B_{M E M}$ in both tissues, the number identified in the tonsils correlated with those enumerated simultaneously from the blood stream and also disappeared rapidly. Thus, parenteral immunization appears to triggers the transient re-circulation of systemic $B_{M E M}$ through the nasopharyngeal mucosa rather than inducing a $\mathrm{B}_{\mathrm{MEM}}$ population localizing to and subsequently maintained at the site.

The difficulties of generating sustained mucosal immunity by the parenteral route are well established. ${ }^{16}$ The route of immunization, whether parenteral or mucosal, determines the subsequent expression of tissue-specific adhesion molecules on $B_{\text {MEM }}$ and, hence, governs their localization to systemic and mucosal sites, respectively. ${ }^{17}$ Consequently, although parenteral immunization induces the predominant expression of L-selectin and chemokines governing the recruitment of lymphocytes to systemic sites, $\alpha_{4} \beta_{7}$ integrin, targeting $B_{\text {MEM }}$ to the mucosa, is dominant only following mucosal priming. ${ }^{18}$ While anamnestic Men $\mathrm{C}$-specific antibody responses have previously been reported in parenterally primed individuals in response to mucosal boosting by the intranasal route, the increases in antibody titer occurring in these studies were both delayed and at a lower level than those induced parenterally. ${ }^{19,20}$ Extending these findings, the data presented here suggest that the responses reported are therefore likely to have reflected the activation of systemic $B_{M E M}$, following the uptake and trafficking of the mucosally delivered antigen to the systemic compartment, ${ }^{21}$ rather than reflecting the activation of PS-specific $\mathrm{B}_{\mathrm{MEM}}$ resident within the nasopharyngeal lymphoid tissue itself.

In addition, the study suggests that, although DT-specific $\mathrm{B}_{\mathrm{MEM}}$ continue to re-circulate through the mucosa as part of the ongoing immune surveillance undertaken by $B_{M E M}$ throughout the lymphoid system, ${ }^{22,23}$ PS-specific $B_{\text {MEM }}$ do not re-circulate in the same way. The findings may, at least in part, reflect the greater number of doses of DT containing vaccines received by the study subjects when compared with the single Men $\mathrm{C}$ vaccine received by the $\mathrm{C}_{\mathrm{PRIMED}}$ individuals. However, the differences were also demonstrated in children, who had received more comparable three and four dose schedules of the PS and PT containing vaccines, respectively, suggesting that the number of doses per se is unlikely to entirely explain the finding unless a given threshold must be reached before any re-circulation occurs. Differences in the sensitivity of the $\mathrm{B}_{\mathrm{MEM}}$ assay for PS and PT antigens are also possible, although the quantitatively similar responses to Men C and DT in the $\mathrm{C}_{\text {PRIMED }}$ individuals following boosting suggest that this too is unlikely to be the solely responsible for the observation. Instead, the findings may reflect the distinct immunological nature of the two antigens and the B-cell subsets they stimulate. In murine models, PS antigens stimulate marginal zone $\mathrm{B}$-cells, which are confined to the marginal zone of the spleen, and B-1 B-cells, which are localized to the pleural and peritoneal cavities. ${ }^{24,25}$ In contrast, PT antigens stimulate follicular B-cells, the predominant re-circulating B-cell population. ${ }^{26}$ Although such B-cell subsets are incompletely defined either phenotypically or functionally in humans, asplenic individuals are at an increased risk of infections with encapsulated organisms, and also respond significantly less effectively, not only to PS, but also to PS-conjugate vaccines than those with normal splenic function. ${ }^{27,28}$ Furthermore, extra-follicular B-cells in humans, which have been equated to the marginal zone population in mice, are similarly confined to secondary lymphoid tissues and are not readily identified in the circulation. ${ }^{29,30}$ Thus, the transience with which the PS-specific $\mathrm{B}_{\mathrm{MEM}}$ are identified in either the blood or the tonsil following vaccination may reflect the rapid localization of these distinct B-cell populations to the spleen or other systemic lymphoid tissues.

The observed absence of PS-specific $\mathrm{B}_{\mathrm{MEM}}$ within the mucosal immune tissue of the nasopharynx is significant as a $\mathrm{B}_{\mathrm{MEM}}$ population maintained at this site of initial colonization could reasonably be expected to enhance the long-term protection conferred, both to the individual and the population, by the conjugate vaccines. PS-specific $\mathrm{B}_{\mathrm{MEM}}$ have been shown to respond to re-challenge in as little as 2-3 days and to re-establish protective antibody concentrations within 5 days of boosting. ${ }^{31}$ Although the interval between initial colonization and subsequent invasion is likely to be variable, carriage durations of between 1 and 7 weeks have been reported in the small number of cases occurring in meningococcal carriage studies. ${ }^{32-34}$ In the context of colonization, meningococci can be found deep to the tonsillar epithelium suggesting that the mucosal surface itself is unlikely to act as a barrier to $\mathrm{B}_{\mathrm{MEM}}$ activation under these circumstances. ${ }^{35}$ In addition, $\mathrm{B}_{\mathrm{MEM}}$ at the site constitutively express co-activation markers and are therefore primed to rapidly differentiate into plasma cells upon bacterial encounter. ${ }^{36,37}$ Thus, the activation of PS-specific $\mathrm{B}_{\mathrm{MEM}}$ in the mucosa would be expected to boost local mucosal immunity within the time frame necessary to prevent subsequent invasion, whereas the 
rate of disease progression once invasion has occurred appears to render futile the response of a population, which is only maintained at systemic sites.

The activation of PS-specific $B_{\text {MEM }}$ within the nasopharynx would not only be expected to halt the stepwise progression from colonization to invasion but also to sustain herd protection. Even in the absence of colonization by meningococci expressing a given PS capsule type, mucosal $\mathrm{B}_{\mathrm{MEM}}$ may differentiate in response to non-antigen-specific signals provided by other infectious agents within the nasopharynx. The activation of innate pattern recognition receptors by conserved pathogen-associated molecular patterns has been shown to trigger $\mathrm{B}_{\mathrm{MEM}}$ differentiation in the absence of other signals. ${ }^{38,39}$ Likewise, bystander T-cells stimulated by unrelated $\mathrm{PT}$ antigens are able to drive the same process. ${ }^{39}$ By these means, mucosal immunity could be sustained through the continued differentiation of PS-specific $B_{\text {MEM }}$ in the nasopharynx even before the waning of herd protection and the resurgent carriage of meningococci expressing a given capsule type.

The data additionally demonstrated differences in the immunity generated against the different PS in the vaccine. Although the Men A antibody and $\mathrm{B}_{\mathrm{MEM}}$ responses echoed the Men C responses in the $\mathrm{C}_{\mathrm{PRIMED}}$ individuals, the Men $\mathrm{W}_{135}$ and Men $\mathrm{Y}$ responses were consistent with the Men $\mathrm{C}$ responses generated in $\mathrm{C}_{\text {NAIVE }}$ subjects. Raised Men A antibody concentrations have been reported previously in the predominately unvaccinated UK population, where Men A is rare as either a carriage or disease isolate. ${ }^{15}$ The titers have been considered to represent the induction of cross-reactive antibodies against the PS capsules of colonizing enteric bacteria. ${ }^{15,40}$ However, given the T-cell-independent nature of PS responses, even in the context of a whole bacterium, ${ }^{41}$ the explanation appears inconsistent with the findings of this study, which suggest that the priming event induces not only an antibody response but also a $B_{M E M}$ population, able to respond to subsequent boosting with the Men A PS itself. These findings may instead represent immunity induced through encounter with a ubiquitous cross-reactive T-cell-dependent peptide antigen. Vaccinating mice with conjugated peptide-haptens has been shown to induce antibodies binding with high affinity to capsular PS, including the Men A PS, and protection in bacterial challenge models has been demonstrated using this approach. ${ }^{42,43}$ The Men A-specific responses demonstrated here suggest that such a phenomenon may also occur in humans and consequently using peptides to prime for cross-reactive PS-specific immunity could represent a novel strategy to overcome the $\mathrm{T}$-cell independence of a range of PS antigens.

In conclusion, the data suggest that strategies to induce PSspecific $B_{M E M}$ in the nasopharyngeal mucosa could significantly impact on the capacity of the conjugate vaccines to sustain immunity against invasive disease as well as potentiating the herd protection the vaccines generate. Such approaches might include the delivery of vaccines by the intranasal, sublingual, or transdermal routes, all of which have been shown to induce antibody production in the upper-respiratory tract, and could be assessed both in isolation or as an adjunct to parenteral immunization. ${ }^{44}$ The success of such strategies is likely to depend on the development of suitable delivery systems and effective mucosal adjuvants and a number of these are already in the pipeline. ${ }^{44,45}$ Enhancing mucosal immunity in this way would be expected to afford additional protection to infants, in whom antibodies wane most rapidly, without the need for serial booster immunizations, as well as extending herd protection in the population as a whole.

\section{METHODS}

Clinical study. All adults (18-40 years of age, $n=32)$ were recruited from a group of otherwise healthy volunteers with no history of atopy or meningococcal disease, undergoing routine tonsillectomy for airway obstruction or tonsillitis. The interval between recruitment and tonsillectomy was between 1 and 6 weeks and was necessarily governed by the routine waiting list for surgery at the recruitment sites. None of the subjects had received a Men A-, Men $\mathrm{W}_{135^{-}}$, or Men Y-containing vaccine previously. A group of subjects who had received a Men $\mathrm{C}$ conjugate vaccine between 5 and 6 years before the current study as part of the catch-up campaign undertaken when the vaccine was first introduced into the UK schedule $\left(\mathrm{C}_{\mathrm{PRIMED}}\right)$, and a group of individuals who were naive to the vaccine $\left(\mathrm{C}_{\text {NAIVE }}\right)$ were recruited, allowing the effect of prior Men $\mathrm{C}$ conjugate vaccination to be determined. No distinction was possible between those who had received a Men $\mathrm{C}$ conjugate vaccine using TT, and those who had received a vaccine using cross-reactive material-197 $\left(\mathrm{CRM}_{197}\right)$, the non-toxic diphtheria toxin mutant, as the carrier PT. All the subjects in the study had been vaccinated against diphtheria, although none in the 5-6 years interval since the $\mathrm{C}_{\text {PRIMED }}$ subjects had received the Men $\mathrm{C}$ conjugate vaccine.

Vaccine recipients received a single intramuscular dose of a Men ACWY-CRM $_{197}$ conjugate vaccine (Novartis Vaccines, Frimley, UK), which contains $10 \mu \mathrm{g}$ of Neisseria meningitidis serogroup A PS, $5 \mu \mathrm{g}$ Neisseria meningitidis serogroup C PS, $5 \mu \mathrm{g}$ Neisseria meningitidis serogroup $\mathrm{W}_{135}$ PS, and $5 \mu \mathrm{g}$ Neisseria meningitidis serogroup Y PS all conjugated to $10-33 \mu \mathrm{g}$ of $\mathrm{CRM}_{197}$. Control subjects did not receive the vaccine before tonsillectomy.

Peripheral blood and saliva samples were collected before vaccination, and tonsillar tissue, along with further blood and saliva samples, were collected, between 1 and 6 weeks later, at the time of surgery. An additional blood and saliva samples were collected at 4 weeks following vaccination in all subjects. Serum and salivary antibodies, representing the final B-cell effector mechanisms in the systemic and mucosal immune compartments, respectively, were analyzed before and at 4 weeks following vaccination. The systemic re-circulation of $\mathrm{B}_{\mathrm{MEM}}$ was examined in the peripheral blood. Mucosal $\mathrm{B}_{\mathrm{MEM}}$ responses were examined in tonsillar tissue. The tonsils are integral to Waldeyer's ring, which defines the mucosal-associated secondary lymphoid tissue of the human nasopharynx. As such, in contrast to peripheral blood, the tonsils represent both an induction and maintenance site for the mucosal immune response in the nasopharynx. ${ }^{36}$

In addition, a group of otherwise healthy children (24-40 months of age; $n=15$ ), with no history of atopy of meningococcal diseases, undergoing routine tonsillectomy for airway obstruction or recurrent infection were recruited. All the children had received three Men C conjugate vaccines, as well as four vaccines containing DT and TT, the last being a Men C-TT conjugate vaccine administered routinely at between 12 and 13 months of age.

The research was authorized by the North Somerset and South Bristol, and the Southmead Research Ethics Committees (references 07/Q2006/79 and E4388), University Hospitals Bristol NHS Foundation Trust Research and Effectiveness Department (reference PA/2006/2485), North Bristol NHS Trust Research and Effectiveness Department and the Medicines and Healthcare Products Regulatory Agency (Eudract 
number 2007-000048-28). All trial-related activities were conducted with informed consent and in accordance with relevant local and national guidelines.

Sample collection. Saliva samples were collected on a sterile sponge (Malvern Medical Developments, Worcester, UK), as previously described. ${ }^{46}$ Saliva and serum samples were frozen at $-80^{\circ} \mathrm{C}$ before processing. Palatine tonsillar tissue was collected into transport medium consisting of RPMI 1640 (Invitrogen, Paisley, UK) with $1,000 \mathrm{iU} \mathrm{ml}^{-1}$ of penicillin and $1 \mathrm{mg} \mathrm{ml}^{-1}$ streptomycin (Sigma-Aldrich, Dorset, UK) for the extraction of TMNCs.

Serum and salivary antibody assays. Men A-, Men C-, $\mathrm{MenW}_{135^{-}}$, and Men Y-specific serum and salivary IgG concentrations were determined using a tetraplex flow cytometry-based assay as previously reported. ${ }^{47}$

Isolation of mononuclear cells from peripheral blood and tonsillar tissue. Peripheral blood mononuclear cells (PBMCs) were isolated from $45 \mathrm{ml}$ of peripheral venous blood, as previously reported. ${ }^{48}$ Briefly, plasma was separated by centrifugation $\left(400 \mathrm{~g}, 20^{\circ} \mathrm{C}, 10 \mathrm{~min}\right)$ and discarded. The remaining packed cells were diluted to a total volume to $45 \mathrm{ml}$ using complete medium, consisting of RPMI 1640 (Invitrogen) with $10 \mathrm{~mm}$ HEPES (Sigma-Aldrich), $100 \mathrm{iU} \mathrm{ml}^{-1}$ penicillin, $0.1 \mathrm{mg} \mathrm{ml}^{-1}$ streptomycin (Sigma-Aldrich), and $2 \mathrm{~mm}$ L-glutamine (Sigma-Aldrich). The cells were layered in $15 \mathrm{ml}$ volumes onto $10 \mathrm{ml}$ of Histopaque 1077 (Sigma-Aldrich) at room temperature. PBMCs were isolated by density gradient centrifugation $\left(400 \mathrm{~g}, 20^{\circ} \mathrm{C}, 40 \mathrm{~min}\right)$ and washed three times (50 ml complete medium, $400 \mathrm{~g}, 4^{\circ} \mathrm{C}, 10 \mathrm{~min}$ ) before cell counting using a hemocytometer.

TMNCs were isolated from tonsillar tissue as previously reported. ${ }^{49}$ Briefly, tissue was dissected into $1-2 \mathrm{~mm}^{3}$ pieces using a scalpel and dispersed through a stainless steel mesh (Potter and Son, Bristol, UK). Remaining cell clumps were allowed to settle and the resulting single-cell suspension was separated into a fresh tube. Following a wash step $(50 \mathrm{ml}$ complete medium, $400 \mathrm{~g}, 20^{\circ} \mathrm{C}, 10 \mathrm{~min}$ ) the cells were re-suspended in a $50 \mathrm{ml}$ of fresh complete medium and layered in $25 \mathrm{ml}$ volumes onto $15 \mathrm{ml}$ of Histopaque 1077 (Sigma-Aldrich) at room temperature. TMNCs were isolated by density gradient centrifugation $\left(400 \mathrm{~g}, 20^{\circ} \mathrm{C}, 25 \mathrm{~min}\right)$ and washed three times ( $50 \mathrm{ml}$ complete medium, $400 \mathrm{~g}, 4^{\circ} \mathrm{C}, 10 \mathrm{~min}$ ) before cell counting using a hemocytometer.

Memory ELISpot assays. Isolated PBMC and TMNC were cultured in complete medium with $10 \%$ fetal calf serum at a concentration of $1 \times 10^{6}$ per ml, following their stimulation with $0.001 \%(\mathrm{w} / \mathrm{v})$ standardized Staphylococcus aureus Cowan (Calbiochem, Merck Biosciences, Middlesex, UK) and $20 \mathrm{ng} \mathrm{ml}^{-1}$ of interleukin-2 (Sigma-Aldrich). Following a 6-day culture, the cells were washed three times, and re-suspended in complete medium with $10 \%$ fetal calf serum.

The antibody-secreting cells present at 6 days, representing the $B_{M E M}$ present at the start of culture, were enumerated from within the PBMC and TMNC populations, as previously described. ${ }^{50}$ MultiscreenTMIP 96-well filter plates (Millipore, Watford, UK) were coated at $4^{\circ} \mathrm{C}$ overnight with the following solutions made up in sterile phosphatebuffered saline. Purified meningococcal serogroup A, C, $\mathrm{W}_{135}$, and Y capsular PS (NIBSC, Potters Bar, UK, product numbers 98/722, 08/214, $01 / 428,01 / 426$, respectively) were used at a concentration of $5 \mu \mathrm{g} \mathrm{ml}^{-1}$ in $5 \mu \mathrm{g} \mathrm{ml}^{-1}$ methylated human serum albumin (mHSA; NIBSC, product number 04/142). Purified DT (NIBSC, product number 69/017) was used at a concentration of $5 \mathrm{Lfml}^{-1}$. Before use, each well was washed gently with $100 \mu$ of sterile phosphate-buffered saline and blocked for $1 \mathrm{~h}$ at $37^{\circ} \mathrm{C}$ with $2 \%$ bovine serum albumin (Sigma-Aldrich). The blocking solution was removed and $50 \mu \mathrm{l}$ of complete medium with $10 \%$ fetal calf serum (Sigma-Aldrich) was added to each well immediately before use.

The cultured cells were plated in $100 \mu$ volumes onto the previously prepared 96-well plates in triplicate at both $2 \times 10^{5}$ and $5 \times 10^{4}$ cells per well (cell concentration before culture). The cells were re-cultured on the
ELISpot plate overnight and the plate washed 12 times with wash buffer (0.05\% Tween 20 (Sigma-Aldrich)).

$\gamma$-Chain-specific goat anti-human IgG conjugated to alkaline phosphatase (Sigma-Aldrich) was added to each well in $100 \mu$ volumes following a 1:2,000 dilution and allowed to bind overnight at $4^{\circ} \mathrm{C}$. The plates were then washed six times with wash buffer. Spots were developed with the $100 \mu \mathrm{l}$ of $2.3 \mathrm{mM} 5$-bromo-4-chloro-3-indolyl phosphate (Sigma-Aldrich) dissolved in 2-amino-2-methyl-1-propanol (Sigma-Aldrich) buffer at a $\mathrm{pH}$ of 10.25 . The reaction was stopped by washing twice with tap water. Spots were counted using a Bioreader 4000 (Bio-Sys GmbH, Karben, Germany). The lower of the two cell concentrations was used for subsequent analysis unless no spots were counted at that concentration.

Statistics. All data were analyzed using GraphPad PRISM (version 5.0). Paired comparisons were made using two-tailed Wilcoxon matched pairs tests. Non-paired comparisons were made using two-tailed MannWhitney tests. Multiple comparisons were made using appropriate oneway ANOVAs with Dunn's multiple comparisons test. Linear regression was used to analyses correlations. $P$ values of $<0.05$ were considered to be significant.

\section{ACKNOWLEDGMENTS}

We gratefully acknowledge the help of all the subjects enrolled in this study and to Novartis for donating the Men ACWY vaccine used in parts of the work. This study was funded by the David Baum Trust.

\section{DISCLOSURE}

AF undertakes research, advisory work, and post-graduate teaching for Novartis, who make one of the conjugate meningococcal vaccines used in this study. All related income is paid to his employers, the University of Bristol and University Hospitals Bristol NHS Foundation Trust. AF is a member of the UK Joint committee on Vaccines and Immunization subcommittee on adolescent immunization and the World Health Organisation European Technical Advisory Group of Experts. RB and JF perform contract research on meningococcal vaccines on behalf of the Health Protection Agency for Baxter Biosciences, GSK, Merck, Novartis, Pfizer, Sanofi Pasteur, and Sanofi Pasteur MSD. JF has received assistance for attendance at Scientific meetings and Advisory boards from Baxter Biosciences, GSK and Novartis; any consultancy fees are paid to the HPA. PMD is a full-time employee of Novartis Vaccines whose compensation includes stock options. ETC, RSH, and NAW have no conflicts of interest to disclose.

\section{Authorship contributions}

ETC, AF, RSH, and NAW designed the research. ETC collected data. ETC, $\mathrm{JF}$, and RB performed experiments. ETC, AF, NAW, and RSH analyzed the results. All authors interpreted the data and wrote the manuscript.

\section{2013 Society for Mucosal Immunology}

\section{REFERENCES}

1. Pollard, A.J., Perrett, K.P. \& Beverley, P.C. Maintaining protection against invasive bacteria with protein-polysaccharide conjugate vaccines. Nat. Rev. Immunol. 9, 213-220 (2009).

2. Perrett, K.P. et al. Immunogenicity and immune memory of a nonadjuvanted quadrivalent meningococcal glycoconjugate vaccine in infants. Pediatr. Infect. Dis. J. 28, 186-193 (2009).

3. Snape, M.D. et al. Immunogenicity of a tetravalent meningococcal glycoconjugate vaccine in infants: a randomized controlled trial. JAMA 299, 173-184 (2008)

4. Maiden, M.C. et al. Impact of meningococcal serogroup C conjugate vaccines on carriage and herd immunity. J. Infect. Dis. 197, 737-743 (2008).

5. Ramsay, M.E., Andrews, N.J., Trotter, C.L., Kaczmarski, E.B. \& Miller, E. Herd immunity from meningococcal serogroup $\mathrm{C}$ conjugate vaccination in England: database analysis. BMJ 326, 365-366 (2003). 
6. Plotkin, S.A. Correlates of protection induced by vaccination. Clin. Vaccine Immunol. 17, 1055-1065 (2010).

7. Auckland, C. et al. Clinical and immunologic risk factors for meningococcal $\mathrm{C}$ conjugate vaccine failure in the United Kingdom. J. Infect. Dis. 194, 1745-1752 (2006).

8. Trotter, C.L., Andrews, N.J., Kaczmarski, E.B., Miller, E. \& Ramsay, M.E. Effectiveness of meningococcal serogroup $C$ conjugate vaccine 4 years after introduction. Lancet 364, 365-367 (2004).

9. McVernon, J., Mitchison, N.A. \& Moxon, E.R. Thelper cells and efficacy of Haemophilus influenzae type b conjugate vaccination. Lancet Infect. Dis. 4, 40-43 (2004).

10. Black, S. et al. Immunogenicity and tolerability of a quadrivalent meningococcal glycoconjugate vaccine in children $2-10$ years of age. Vaccine 28, 657-663 (2010).

11. Gasparini, R. et al. Randomized trial on the safety, tolerability, and immunogenicity of MenACWY-CRM, an investigational quadrivalent meningococcal glycoconjugate vaccine, administered concomitantly with a combined tetanus, reduced diphtheria, and acellular pertussis vaccine in adolescents and young adults. Clin. Vaccine Immunol. 17, 537-544 (2010).

12. Halperin, S.A., Diaz-Mitoma, F., Dull, P., Anemona, A. \& Ceddia, F. Safety and immunogenicity of an investigational quadrivalent meningococcal conjugate vaccine after one or two doses given to infants and toddlers. Eur. J. Clin. Microbiol. Infect. Dis. 29, 259-267 (2010).

13. Khatami, A. et al. Persistence of the immune response at 5 years of age following infant immunisation with investigational quadrivalent MenACWY conjugate vaccine formulations. Vaccine 16, 2831-2838 (2012).

14. Snape, M.D. et al. Seroprotection against serogroup $C$ meningococcal disease in adolescents in the United Kingdom: observational study. BMJ 336, 1487-1491 (2008).

15. Trotter, C.L. et al. Seroprevalence of antibodies against serogroup $C$ meningococci in England in the postvaccination era. Clin. Vaccine Immunol. 15, 1694-1698 (2008).

16. Neutra, M.R. \& Kozlowski, P.A. Mucosal vaccines: the promise and the challenge. Nat. Rev. Immunol. 6, 148-158 (2006).

17. Brandtzaeg, P. \& Johansen, F.E. Mucosal B cells: phenotypic characteristics, transcriptional regulation, and homing properties. Immunol. Rev. 206, 32-63 (2005).

18. Quiding-Jarbrink, M. et al. Differential expression of tissue-specific adhesion molecules on human circulating antibody-forming cells after systemic, enteric, and nasal immunizations. A molecular basis for the compartmentalization of effector B cell responses. J. Clin. Invest. 99, 1281-1286 (1997).

19. Findlow, H. et al. Serum antibody kinetics following nasal or parenteral challenge with meningococcal polysaccharide in healthy adults. Clin. Vaccine Immunol. 18, 424-429 (2011).

20. Wing, J.B. et al. Kinetics of immune responses to nasal challenge with meningococcal polysaccharide one year after serogroup-C glycoconjugate vaccination. Clin. Infect. Dis. 52, 1317-1323 (2011).

21. MacPherson, G.G. \& Liu, L.M. Dendritic cells and Langerhans cells in the uptake of mucosal antigens. Curr. Top Microbiol. Immunol. 236, 33-53 (1999).

22. Cariappa, A. et al. The recirculating B cell pool contains two functionally distinct, long-lived, posttransitional, follicular B cell populations. J. Immunol. 179, 2270-2281 (2007).

23. Miyasaka, M. \& Tanaka, T. Lymphocyte trafficking across high endothelial venules: dogmas and enigmas. Nat. Rev. Immunol. 4, 360-370 (2004).

24. Martin, F. \& Kearney, J.F. B1 cells: similarities and differences with other B cell subsets. Curr. Opin. Immunol. 13, 195-201 (2001).

25. Martin, F. \& Kearney, J.F. Marginal-zone B cells. Nat. Rev. Immunol. 2, 323-335 (2002).

26. Pillai, S. \& Cariappa, A. The follicular versus marginal zone B lymphocyte cell fate decision. Nat. Rev. Immunol. 9, 767-777 (2009).

27. Balmer, P. et al. Immune response to meningococcal serogroup $C$ conjugate vaccine in asplenic individuals. Infect. Immun. 72, 332-337 (2004).
28. Stoehr, G.A. et al. Mode of splenectomy and immunogenicity of meningococcal vaccination in patients with hereditary spherocytosis. Br. J. Surg. 95, 466-471 (2008).

29. Spencer, J., Perry, M.E. \& Dunn-Walters, D.K. Human marginal-zone B cells. Immunol. Today 19, 421-426 (1998).

30. Dono, M. et al. Subepithelial B cells in the human palatine tonsil. II. Functional characterization. Eur. J. Immunol. 26, 2043-2049 (1996).

31. Tsai, T.F. et al. Early appearance of bactericidal antibodies after polysaccharide challenge of toddlers primed with a group $\mathrm{C}$ meningococcal conjugate vaccine: what is its role in the maintenance of protection? Clin. Vaccine Immunol. 13, 854-861 (2006).

32. Ala'Aldeen, D.A. et al. Dynamics of meningococcal long-term carriage among university students and their implications for mass vaccination. J. Clin. Microbiol. 38, 2311-2316 (2000).

33. Edwards, E.A., Devine, L.F., Sengbusch, G.H. \& Ward, H.W. Immunological investigations of meningococcal disease. III. Brevity of group C acquisition prior to disease occurrence. Scand J. Infect. Dis. 9, 105-110 (1977).

34. Goldschneider, I., Gotschlich, E.C. \& Artenstein, M.S. Human immunity to the meningococcus. II. Development of natural immunity. J. Exp. Med. 129, 1327-1348 (1969).

35. Sim, R.J., Harrison, M.M., Moxon, E.R. \& Tang, C.M. Underestimation of meningococci in tonsillar tissue by nasopharyngeal swabbing. Lancet 356, 1653-1654 (2000).

36. Brandtzaeg, P. \& Pabst, R. Let's go mucosal: communication on slippery ground. Trends Immunol. 25, 570-577 (2004).

37. Liu, Y.J. et al. Memory B cells from human tonsils colonize mucosal epithelium and directly present antigen to $T$ cells by rapid up-regulation of B7-1 and B7-2. Immunity 2, 239-248 (1995).

38. Bernasconi, N.L., Onai, N. \& Lanzavecchia, A. A role for Toll-like receptors in acquired immunity: up-regulation of TLR9 by BCR triggering in naive $B$ cells and constitutive expression in memory B cells. Blood 101, 4500-4504 (2003).

39. Bernasconi, N.L., Traggiai, E. \& Lanzavecchia, A. Maintenance of serological memory by polyclonal activation of human memory B cells. Science 298, 2199-2202 (2002).

40. Guirguis, N. et al. Escherichia coli K51 and K93 capsular polysaccharides are crossreactive with the group A capsular polysaccharide of Neisseria meningitidis. Immunochemical, biological, and epidemiological studies. J. Exp. Med. 162, 1837-1851 (1985).

41. Snapper, C.M. Differential regulation of protein- and polysaccharidespecific lg isotype production in vivo in response to intact Streptococcus pneumoniae. Curr. Protein Pept. Sci. 7, 295-305 (2006).

42. Wu, Y., Zhang, Q., Sales, D., Bianco, A.E. \& Craig, A. Vaccination with peptide mimotopes produces antibodies recognizing bacterial capsular polysaccharides. Vaccine $\mathbf{2 8}, \mathbf{6 4 2 5 - 6 4 3 5}$ (2010).

43. Pincus, S.H., Smith, M.J., Jennings, H.J., Burritt, J.B. \& Glee, P.M. Peptides that mimic the group B streptococcal type III capsular polysaccharide antigen. J. Immunol. 160, 293-298 (1998).

44. Czerkinsky, C. \& Holmgren, J. Topical immunization strategies. Mucosal. Immunol. 3, 545-555 (2010).

45. Lawson, L.B., Norton, E.B. \& Clements, J.D. Defending the mucosa: adjuvant and carrier formulations for mucosal immunity. Curr. Opin. Immunol. 23, 414-420 (2011).

46. Horton, R.E. et al. Influence of age and carriage status on salivary lgA to Neisseria meningitidis. Epidemiol. Infect. 133, 883-889 (2005).

47. Lal, G., Balmer, P., Joseph, H., Dawson, M. \& Borrow, R. Development and evaluation of a tetraplex flow cytometric assay for quantitation of serum antibodies to Neisseria meningitidis serogroups A, C, Y, and W-135. Clin. Diagn. Lab. Immunol. 11, 272-279 (2004).

48. Davenport, V. et al. Mucosal immunity in healthy adults after parenteral vaccination with outer-membrane vesicles from Neisseria meningitidis serogroup B. J. Infect. Dis. 198, 731-740 (2008).

49. Davenport, V. et al. Evidence for naturally acquired T cell-mediated mucosal immunity to Neisseria meningitidis. J. Immunol. 171, 4263-4270 (2003).

50. Iwajomo, O.H. et al. Deteriorating pneumococcal-specific B-cell memory in minimally symptomatic African children with HIV. J. Infect. Dis. 15, 534-543 (2011). 